\title{
Comparative Histological Studies of the Esophagus Wall of Oryctolagus cuniculus Rabbit Adult, Young and Lactating Using Light Microscope
}

\author{
Atteyat Selim*, Hazaa E and Goda W
}

Zoology Department, Faculty of Science, Tanta University, Tanta, Egypt

\begin{abstract}
Background: As the different parts of the alimentary canal, the esophagus is an important part of it, because it facilitate the passage of food material to the stomach. The purpose of this study was to compare the structure of the esophageal wall of rabbit before weaning (lactating) and after weaning (young and adult) to determine the structural changes that accompany the changes of the feeding pattern from lactating to adult.

Result: we collected fifteen rabbit. Five animals were randomly choised from each stage (young after weaning, young before weaning and adult). Esophagus were removed after anesthesia, processed and examined on light electron microscope. Histologically, the esophageal wall of Oryctolagus cunniculus composed of the four layers as any other mammals. mucosa with stratified non keratinized squamous epithelium was observed and it give strong reaction with (PAS) in adult rabbit while in lactating ones it give negative reaction and moderate reaction in young rabbits. Muscularis mucosa layer was absent in lactating rabbit.
\end{abstract}

Conclusion: From these studies, we observed some differences than other mammals may be related to the physiological pattern and behavior of feeding.

Keywords: Esophagus; Rabbit; Lactating; Young-adult; Light microscope; Histochemical studies

\section{Introduction}

Many previous authors describe the digestive organs 1 of other mammals such as Egyptian bats in which showed some differences between them $[1,2]$.

In vertebrate animals the secretion from the gastrointestinal wall contains mucoid substances [3-9]. The histological structure of the esophagus rabbit and guinea pig incomplete. Therefore, the present study was concentrated on rabbit and rat with different stages. The esophagus wall has four layers from inside to outside (mucosa, submucosa, muscularis and serosa). The mucosa is composed of three layers, the stratified squamous epithelium, a lamina propria and a lamina muscularis. The keratinization is different in different mammals in pig and in ruminants.

In African Giant Rats (AGRs), the epithelial lining of the esophagus was non keratinized stratified squamous cells. The mucous glands were absent. Give with Alcian Blue (AB), Periodic Acid Schiff (PAS) and Alcian Blue-Periodic Acid Schiff (ABPAS) negative [10].

The present work aims to illustrate the differences in the histological structure of the esophagus wall of rabbit through lactating and after weaning by the use of light microscope.

\section{Materials and Methods}

\section{Animals}

Fifteen animals of Oryctolagus cuniculus collected alive from AbuRawash, Giza Governorate. Five animals were lactating and depend only on suckling milk from their mothers average weighs were $257 \mathrm{~g}$. five animals were after weaning but before maturity feed on different kinds of food and had free access to water. Their weighs were about 1.0 $\mathrm{kg}$. Five adult animals also were procured also feed on different kinds of food and had free access to water. Their weighs average was $1.99 \mathrm{~kg}$.

\section{Histological examination}

Animals were anesthesied and esophagus of adult, Young, and lactating animals were removed. The esophagus were fixed in $10 \%$ neutral buffered formalin for $24 \mathrm{~h}$. Dehydrated in ascending grades of ethyl alcohol, cleared by xylene and embedded in paraffin. Sections of 5 $\mathrm{lm}$ thickness were mounted and stained with Haematoxylin and Eosin method [11].

\section{Histochemical examination}

Periodic Acid Schiff procedure (PAS). And azan stains used [12].

\section{Statistical analysis}

Statistical presentation and analysis of the present study was conducted, using below.

Mean value $(\bar{x})$ : the sum of all observations divided by the number of observation:

$$
\left(\begin{array}{c}
- \\
\times
\end{array}\right)=\frac{\sum x}{n}
$$

Where $\left(\begin{array}{c}- \\ x\end{array}\right)=$ mean value,

$\sum \mathrm{x}=$ The sum of individual observations,

*Corresponding author: Selim A, Zoology Department, Faculty of Science, Tanta University, Tanta, Egypt, Tel: 02-040-3303691; E-mail: atteyatselim@hotmail.com

Received May 10, 2017; Accepted June 15, 2017; Published June 25, 2017

Citation: Selim A, Hazaa E, Goda W (2017) Comparative Histological Studies of the Esophagus Wall of Oryctolagus cuniculus Rabbit Adult, Young and Lactating Using Light Microscope. J Cytol Histol 8: 456. doi: 10.4172/2157-7099.1000456

Copyright: ( 2017 Selim A, et al. This is an open-access article distributed under the terms of the Creative Commons Attribution License, which permits unrestricted use, distribution, and reproduction in any medium, provided the original author and source are credited. 
Citation: Selim A, Hazaa E, Goda W (2017) Comparative Histological Studies of the Esophagus Wall of Oryctolagus cuniculus Rabbit Adult, Young and Lactating Using Light Microscope. J Cytol Histol 8: 456. doi: 10.4172/2157-7099.1000456

$\mathrm{n}=$ number of observations.

Standrd deviation [SD]: It measures the degree of scatter of individual varieties around their mean: $S D=\sqrt{\frac{\sum|\mathrm{X}-\mathrm{x}|^{-2}}{n-1}}$

Where $\Sigma(x-x)$ is the sum of squares of the difference between each observation $(X)$ and the mean value of all observations $(X)$

Standard student " $t$ test": test of significance of the difference between two means:

The calculated " $\mathrm{t}$ " was compared with tabulated one at different levels of significance at the degree of freedom (DF):

$\mathrm{DF}=(\mathrm{D}+\mathrm{n} 2)-2$

Where:

$\mathrm{X}=$ The mean value of group $\mathrm{L}$,

$\mathrm{X} 2=$ The mean value of group II.

SD1=The standard deviation of group I. SD2=The standard deviation of group II. $\mathrm{n} 1=$ the number of observations of group L,

$\mathrm{n} 2=$ The number of observations of group II.

Analysis of variance [ANOVA] tests: According to the computer program SPSS for Windows. ANOVA test was used for comparison among different times in the same group in quantitative data.

\section{Results}

\section{Morphometric study}

The esophageal length of rabbit was in lactating $3.62 \pm 0.97 \mathrm{~cm}$, in Young $6.97 \pm 0.46 \mathrm{~cm}$ and in adult $8.19 \pm 0.26 \mathrm{~cm}$ (Table 1).

\section{Microscopic study}

Histolgogically, the esophageal wall is composed of mucosa, sub mucosa, muscularis and serosa. The mucosa characterized with a nonkeratinized squamous.

\section{Lactating rabbit}

The esophageal wall composed of serosa of loose connective tissue, the muscularis of three layers (outer longitudinal muscle layermiddle circular muscle layer-inner longitudinal), sub mucosa of loose connective tissue (Lamina propria) and the mucosa of non-keratinized squamous epithelium. All the above layers were poorly developed by using hematoxylin and eosin stain (Figure 1). By using Periodic acid Schiff reagent for mucus secretion, we observed that the muscular layer give strong purple color reaction, weak reaction with inner layer of mucosa and very weak reaction with lamina propria (Figure 2). With azan stain the lamina propria react with aniline blue give weak reaction but the muscular layer react with azocamine and give moderate reaction (Figure 3).

\begin{tabular}{|l|c|c|c|}
\hline Esophagus length rabbit & Lactating & Young & Adult \\
\hline Range & $2-5.2$ & $6.2-7.8$ & $7.8-8.6$ \\
\hline Mean \pm SD & $3.62 \pm 0.97$ & $6.97 \pm 0.46$ & $8.19 \pm 0.26$ \\
\hline F. test & \multicolumn{2}{|c|}{183.286} \\
\hline p. value & \multicolumn{2}{|c|}{0.001} \\
\hline Lactating and Young & Lactating and Adult & Young and Adult \\
\hline 0.001 & \multicolumn{2}{|c|}{0.001} & 0.001 \\
\hline
\end{tabular}

Table 1: Histogram showing the esophageal length $(\mathrm{cm})$ and body weight $(\mathrm{kg})$ of rabbit.

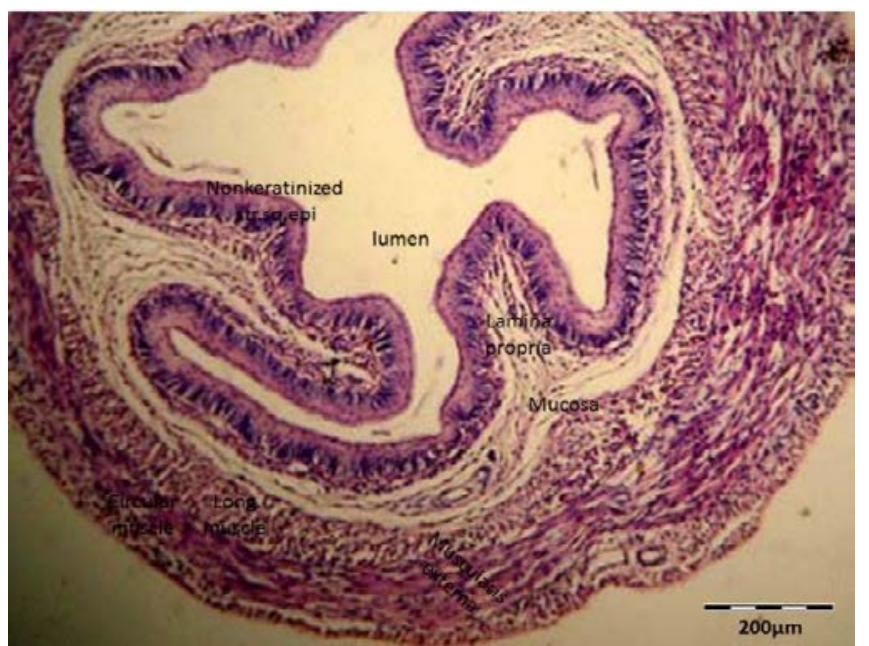

Figure 1: Transverse section of lactating $O$. cuniculus esophagus showing muscularis layer, submucosa, and mucosa contain non keratinized stratified squamous epithelium H\&E.

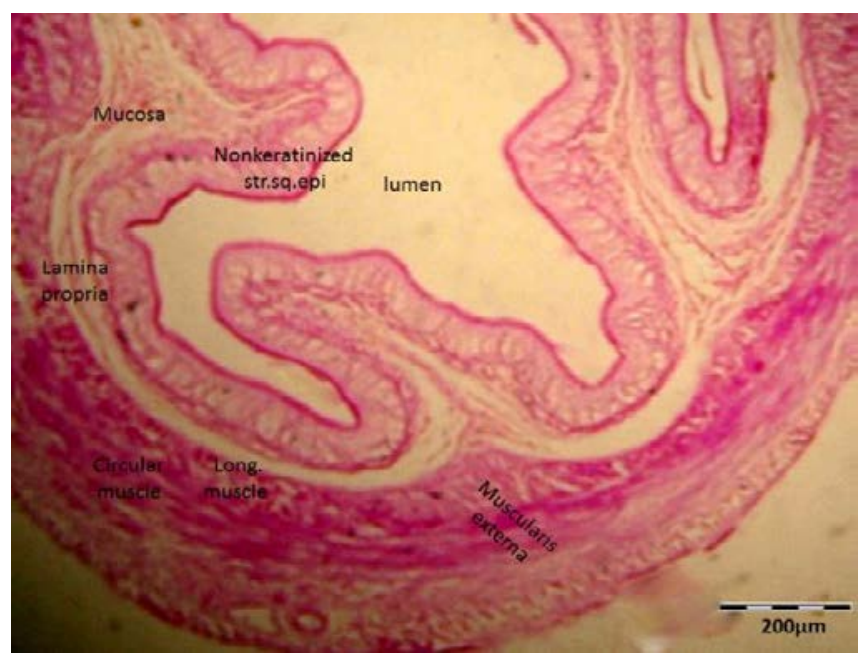

Figure 2: Transverse section of lactating $O$. cuniculus esophagus showing strong reaction with muscularis layer, weak reaction with inner layer of mucosa (lumen) and very weak reaction with basal lamina PAS.

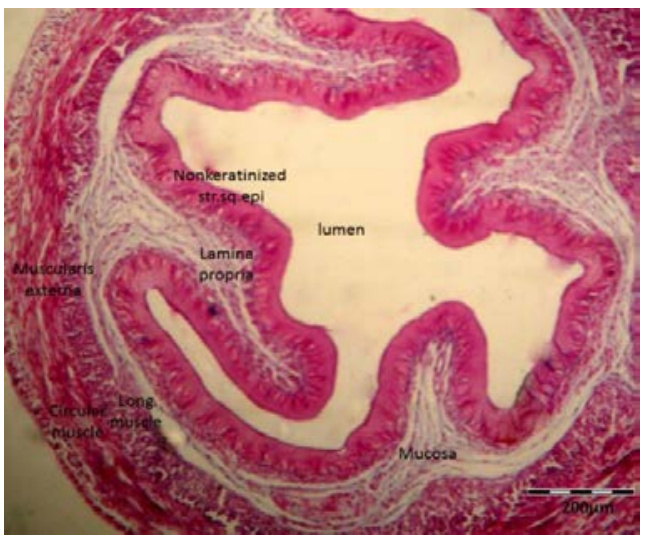

Figure 3: Transverse section of lactating $O$. cuniculus esophagus showing muscularis layer, submucosa, and mucosa contain lamina propria and nonkeratinized stratified squamous epithelium Azan. 
Citation: Selim A, Hazaa E, Goda W (2017) Comparative Histological Studies of the Esophagus Wall of Oryctolagus cuniculus Rabbit Adult, Young and Lactating Using Light Microscope. J Cytol Histol 8: 456. doi: 10.4172/2157-7099.1000456

\section{Young rabbit}

The esophog wall composed of serosa of loose connective tissue, the muscularis three layers (outer longitudinal muscle layer and the inner longitudineal) more thickness than lactating rabbit, submucosa of loose connective tissue (Lamina propria) containing blood vessels and nerve ending, thin muscularis mucosa and mucosa of nonkeratinized squamous epithelium more thickness than lactating rabbit. The entire above developed layer give moderately. All the above layers were developed by using hematoxylin and eosin stain (Figure 4). By using Periodic acid Schiff reagent for mucus secretion, we observed that the muscular layer give negative reaction, very weak reaction with inner layer of mucosa and very weak also reaction with lamina propria (Figure 5). With azan stain the lamina propria react with aniline blue give negative reaction but the muscular layer react with azocamine and give moderate reaction (Figure 6).

\section{Adult rabbit}

The esophageal wall composed of serosa of loose connective tissue, the muscularis three layers (outer longitudinal muscle layer and the inner longitudineal ) more thickness than young rabbit, submucosa of loose connective tissue (Lamina propria), thin muscularis mucosa and mucosa of non-keratinized squauamous epithelium more thickness than young rabbit. All the above layers were well developed by using hematoxylin and eosin stain (Figure 7). By using Periodic acid Schiff reagent for mucus secretion, we observed that the muscular layer give

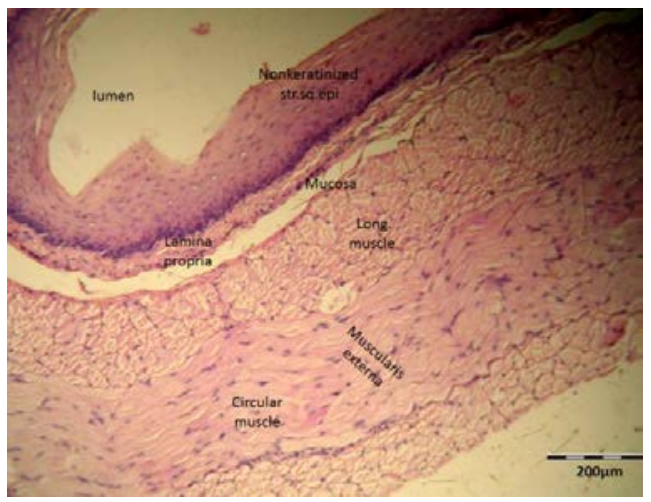

Figure 4: Transverse section of young $O$. cuniculus esophagus showing muscularis layer, submucosa, and mucosa contain thin layer of muscularis mucosa and non-keratinized stratified squamous epithelium H\&E.

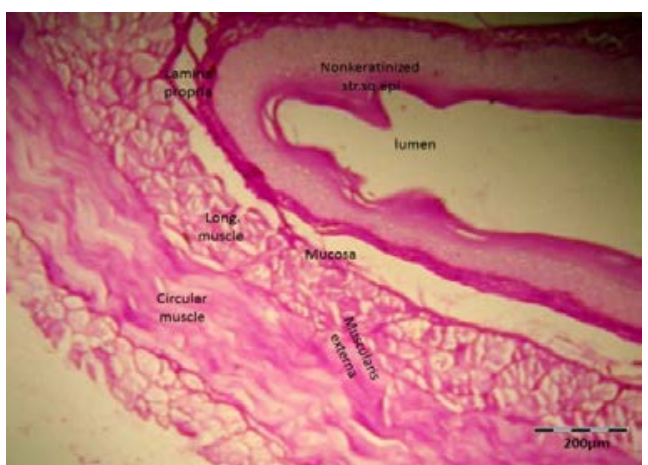

Figure 5: Transverse section of young $O$. cuniculus esophagus showing moderate reaction with muscularis layer, inner layer of mucosa (linning lumen) and basal lamina PAS.

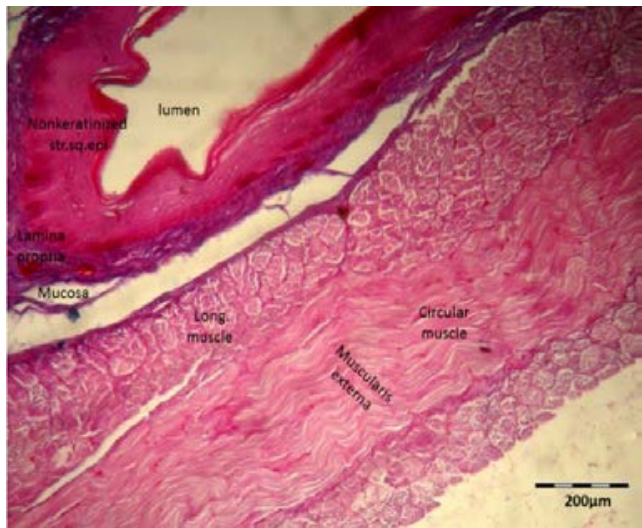

Figure 6: Transverse section of lactating $O$. cuniculus esophagus showing muscularis layer, submucosa, and mucosa contain lamina propria and nonkeratinized stratified squamous epithelium, Azan.

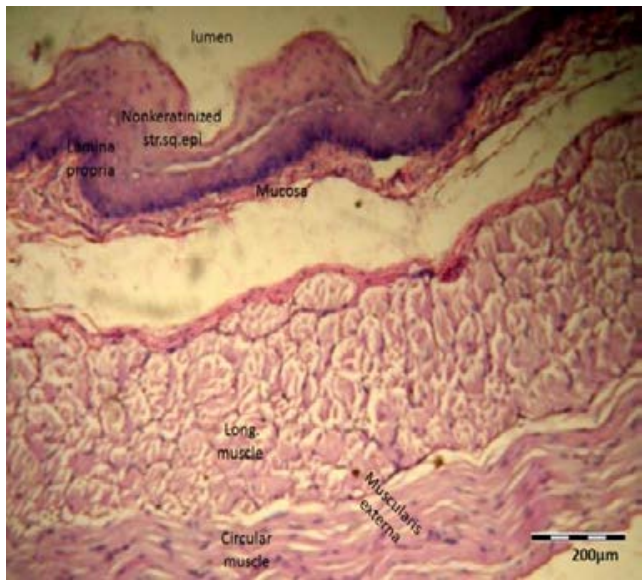

Figure 7: Transverse section of adult $O$. cuniculus esophagus showing muscularis layer, submucosa, and mucosa contain muscularis mucosa and non-keratinized stratified squamous epithelium H\&E.

poor reaction, strong reaction with inner layer of mucosa and moderate reaction with lamina propria (Figure 8 ). With azan stain the lamina propria react with aniline blue give negative reaction but the muscular layer react with azocamine and give moderate reaction (Figures 9 and 10).

\section{Discussion}

The esophagus is the first part of the alimentary canal and was divided into the cervical, thoracic and abdominal portions. As observed for rabbit [13]. However, Rudolf and Strombery [14] noticed that the esophagus of the rat deviated slightly to the left around the cervical region.

The inner wall of the esophagus in the present animals show non keratinized stratified squamous epithelium as the same observed of the African Giant Rat [8] (Cricetomys gambianus-Waterhouse, 1840) $[10,15]$.

The esophagus is important organ [16] for passage of food from the mouth to the stomach. The present animals (Rabbit - herbivorous needs this mucous to increase the viscosity of the esophagus which is important allowing the passage of large food. The mucous barrier is also an important factor in the protection of the esophagus from damage. In the lactating rabbit the mucus which secreted from the mucosal layer 
Citation: Selim A, Hazaa E, Goda W (2017) Comparative Histological Studies of the Esophagus Wall of Oryctolagus cuniculus Rabbit Adult, Young and Lactating Using Light Microscope. J Cytol Histol 8: 456. doi: 10.4172/2157-7099.1000456

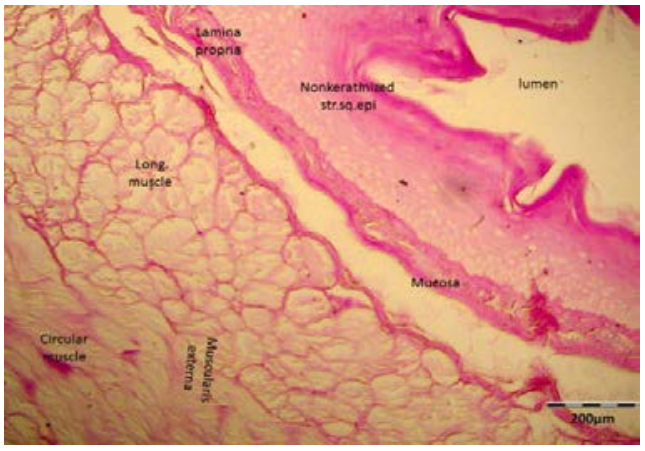

Figure 8: Transverse section of adult $O$. cuniculus esophagus showing weak reaction with muscularis layer and strong reaction with inner layer of mucosa (linning lumen) and basal lamina PAS.

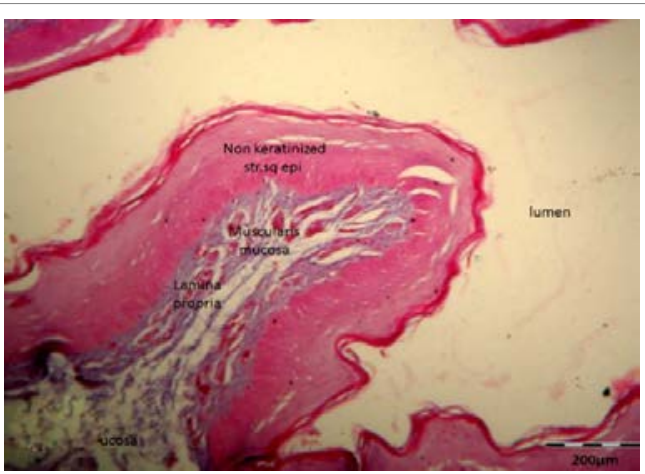

Figure 9: Transverse section of lactating O. cuniculus esophagus showing muscularis layer, submucosa, and mucosa contain lamina propria and nonkeratinized stratified squamous epithelium.

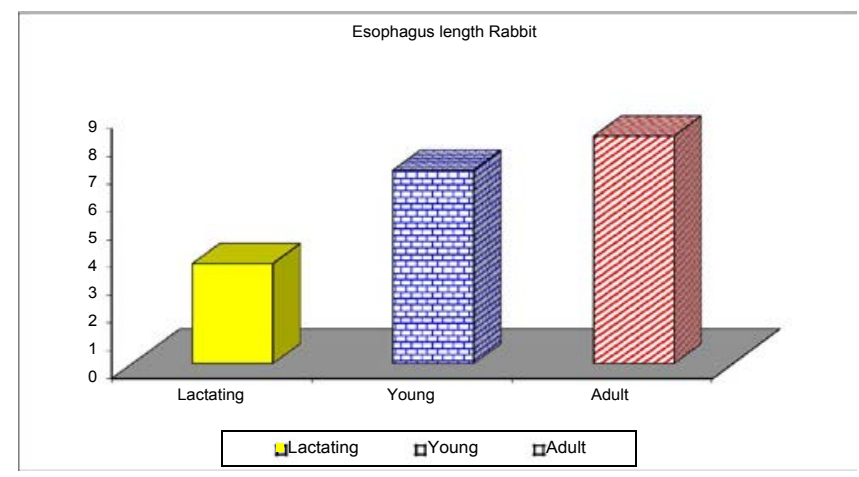

Figure 10: The non-keratinized squamous to Esophageal wall of 3 (Lactating, young, adult) rabbits.

or from the salivary gland give strong reaction may be due to feeding habit. This observation agrees with that of Ali et al. [17] but not with those ones of Elliott et al. [18-20].

\section{Conclusion}

From the present study, it was observed that the esophagus of rabbit had no esophageal glands and lamina muscularis and because of the absence of these glands, histochemical reactions showed $\mathrm{AB}$ and PAS, and AB-PAS negative results. There are structural changes in the rabbit esophagus before, after weaning and after maturity. These changes may be related to the type of food at different stages and feeding habit.

\section{Ethics Approval}

Faculty of Science Tanta University.

\section{Ethics Committee}

Zoology Department - Tanta University.

\section{References}

1. Madkour GA (1977) Comparative study of certain features of the alimentary canal and disposition of the viscera in Egyptian bats, Ann Zool Agra 13: 63-81.

2. Madkour GA, Hammouda EM, Ibrahim IG (1982) Histology of the alimentary tract of two common Egyptian bats, Ann Zool 19: 53-74.

3. Filipe, MI (1979) Mucins in the human gastrointestinal epithelium a review. Invest Cell Pathol 195-216.

4. Allen A (1981) Structure and function of gastrointestinal mucus, Physiology of the Gastrointestinal Tract, Raven Press, New York, pp: 617-639.

5. Suganuma T, Katsuyama T, Tsukahara M, Tatematsu M, Sakakura $Y$, et al. (1981) Comparative histochemical study of alimentary tracts with special reference to the mucous neck cells of the stomach, pp: 219-238.

6. Pedini V, Scocco P, Gargiulo AM, Ceccarelli P (2001) Carbohydrate histochemistry of lamb duodenum. Acta Histochem, pp: 315-323.

7. Liquor GE, Scillitani G, Mastrodonato M, Ferri D (2002) Histochemical investigations on the secretory cells in the oesophagastric tract of the Eurasian green toad, Bufo viridis, Histochem, pp: 517-524.

8. Choi BY, Sohn YS, Choi C, Chae C (2003) Lectin histochemistry for glycoconjugates in the small intestines of piglets naturally infected with Isospora Suis, pp: 389-392.

9. Schumacher U, Duku M, Katoh M, Jorns J, Krause WJ (2004) Histochemical similarities of mucins produced by Brunner's glands and pyloric glands a comparative study, Anat Rec, pp: 540-550.

10. Nzalak J, Oliver, Onyeanusi B, Izuchukwu, Samuel A, et al. (2010) Gross Anatomical, Histological and Histochemical Studies of the Esophagus of the African Giant Rat (AGR) 3: 55-64

11. Bancroft JD, Stevens A 1990 Theory and Practice of histological Techniques, 43-80.

12. Gretchen LH 1974 Animal Tissue Technique

13. Timothy PJ (1990) Comparative gross anatomical studies of the rabbit digestive system. DVM, ABU, Student Project.

14. Rudolf H, Strombery MW (1976) The Digestive System, In: Anatomy of laboratory 43-51.

15. Dellmann H, Brown EM (1987) Histology of the Digestive System. In: Textbook of Veterinary Histology 229-247.

16. Saroseik J, McCallum RW (2000) Mechanism of esophageal mucosal defense, Practical Research in clinical Gastroenterology 14: 701-717.

17. Ali MN, Byanet O, Salami SO, Imam J, Maidawa S, et al. (2008) Gross anatomical aspect of gastrointestinal tract of the wild African giant rat (Cricetomys gambianus). Journal of Scientific Research and Essay 3: 518

18. Elliott JR (2007) Overview of Reptile Biology, Anatomy and Histology, Infectious Diseases and pathology of Reptiles, pp: 1-2.

19. Parillo F, Gargiulo AM, Fagioli O (2005) Complex carbohydrates occurring in the digestive apparatus of Umbrina cirosa (L), Veterinary Research Communication 28: 267-278.

20. Selvan PS, Ushakumary S, Ramesh G (2008) Studies on the histochemistry of proventriclus and gizzard of post hatched Guinea fowl (Numida meleagris). International Journal of Poultry Science 7: 1-4. 